\title{
Hollow Gold Nanoshell Modified Electrode as Electrochemical Biosensor for Hemoglobin and Its Analytical Application
}

\author{
Xiaoqing Li ${ }^{1.2}$, Bo Shao ${ }^{1}$, Yunxiu Sun ${ }^{1}$, Bingxue Zhang ${ }^{1}$, Xianghui Wang ${ }^{1, *}$, Wei Sun ${ }^{1, *}$ \\ ${ }^{1}$ Key Laboratory of Water Pollution Treatment and Resource Reuse of Hainan Province, Key \\ Laboratory of Functional Materials and Photoelectrochemistry of Haikou, College of Chemistry and \\ Chemical Engineering, Hainan Normal University, Haikou 571158, China; \\ ${ }^{2}$ College of Health Sciences, Shandong University of Traditional Chinese Medicine, Jinan, 250355, \\ China. \\ *E-mail: swyy26@hotmail.com and god820403@163.com
}

doi: $10.20964 / 2021.02 .50$

Received: 15 October 2020 / Accepted: 1 December 2020 / Published: 31 December 2020

In this paper hollow gold nanoshell (HGNs) was modified on carbon ionic liquid electrode (CILE), which was used for further immobilization of hemoglobin $(\mathrm{Hb})$ with Nafion film step by step to get an electrochemical $\mathrm{Hb}$ sensor. UV-Vis absorption spectroscopy proved that $\mathrm{Hb}$ was not denatured after mixed with HGNs without change of the Soret band. Electrochemical studies proved the realization of direct electrochemistry of $\mathrm{Hb}$ on the HGNs/CILE and electrochemical parameters were calculated in details. Electrocatalysis, sample detection, and the stability of sensor were also investigated to show the analytical applications of this electrochemical sensor, which extended the usage of HGNs in electrochemical fields.

Keywords: Hollow gold nanoshell; Hemoglobin; Electrochemical sensor; Modified electrode; Carbon ionic liquid electrode

\section{$\underline{\text { FULL TEXT }}$}

(C) 2021 The Authors. Published by ESG (www.electrochemsci.org). This article is an open access article distributed under the terms and conditions of the Creative Commons Attribution license (http://creativecommons.org/licenses/by/4.0/). 